\title{
Author urges scale-up of health care innovation
}

\author{
n Cite as: CMAJ 2017 February 13;189:E253-4. doi: 10.1503/cmaj.1095385
}

mproving the Canadian health care system isn't a matter of fostering innovation, according to Dr. Danielle Martin, vice-president of medical affairs and health system solutions at Women's College Hospital in Toronto. There are plenty of good ideas out there already, and more pop up every day.

"The challenge is spread and scale. It's locating the time and the will and the energy to broadly implement innovations," Martin said during her Jan. 18 presentation in Ottawa called "Big Idea: Scaling up system transformation in Canadian health care." This is but one idea that she wrote about in her new book, Better Now: Six Big Ideas to Improve Health Care for All Canadians.

Unfortunately, there are many barriers to taking good ideas from the local to the national level. Often, the conversation is steered away from a productive path toward the "really, tired, old argument" that medicare is hopelessly broken and the system needs a complete overhaul. Not so, said Martin. We should be thinking improvement, not replacement.

The notion that a single-payer system discourages innovation is also misguided, she said, noting that she has seen no shortage of creative solutions to big health care problems, and many don't require fancy machines or expensive technology.

Restricted access to data on patient outcomes in health care facilities is also a problem, noted Martin. Health care providers are quite adept at justifying their reluctance to publicly disclose information such as hospital infection and readmission rates, but they "fail to see that it is a critical component of the anatomy of large-scale change. In fact, we will not, in my opinion, be able to achieve scaling and spreading of innovative solutions unless we make data publicly available for all to see."

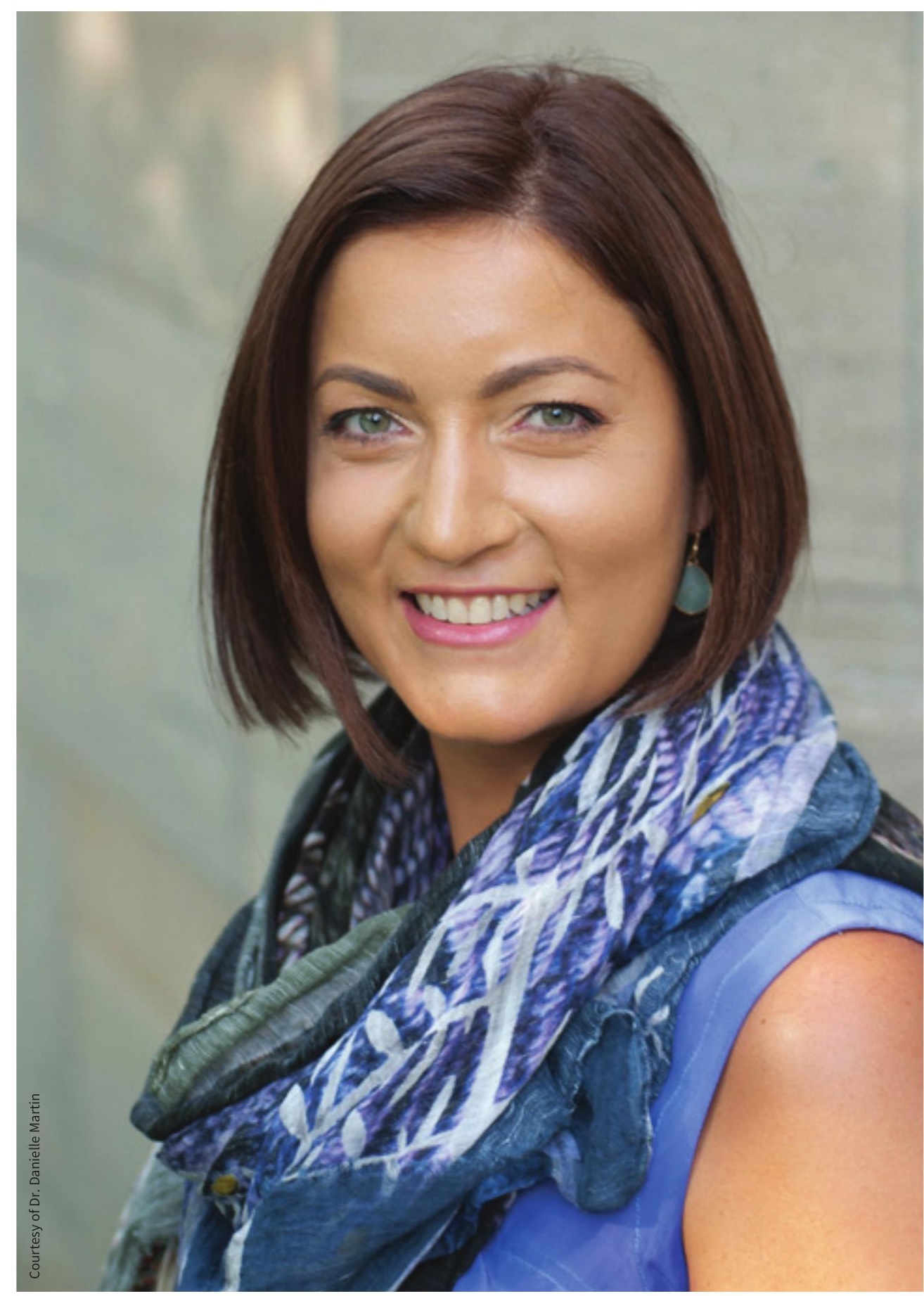

Improving the health care system will require spreading and scaling existing innovations, said Dr. Danielle Martin. 
Even when data are available, and health care leaders make innovative decisions based on the best-available evidence, there will always be resistance to change from some corners. But these leaders must "stick to their guns" and push on, said Martin. Unfortunately, she noted, physicians are sometimes the "feet that drag" in making positive system-level change. Most physicians in Canada act as independent contractors, which has its benefits, such as shielding the doctorpatient relationship from outside influence. But it may also create the sense that doctors, rather than being part of the health care system, operate alongside it, and that their involvement in improvement projects is voluntary.

There is a "pressing, practical need to get all the feet moving together in the same direction, and that is going to require doctors, like me, to think differently about our role."
After her presentation, Martin participated in a panel discussion with Alex Munter, CEO of the Children's Hospital of Ontario; Chris Power, CEO of the Canadian Patient Safety Institute; and Lindee David, CEO of Joule, a Canadian Medial Association company that fosters health care innovation (and owns CMAJ).

According to Munter, it takes a sense of urgency for health care organizations to make changes with the potential to make big impacts on patient care. It also requires health care workers within those organizations to be open to doing things differently. "Fundamentally, it's about a culture of problem solving within the organization, and helping people understand that changing the environment is part of their job," said Munter.

Providing support to physicians with good ideas can also lead to change, noted David. Enterprising doctors may need business help, or access to capital, or simply the "permission to innovate" and move forward with their ideas. "I think we need to think big," said David. "If we don't have a goalpost to drive to, we're not going to get there. I feel that physicians, in conjunction with patients, will make the difference in terms of the innovations we need."

In the end, however, it won't be those who work in the health care system that drive transformation, according to Power. There is too much vested interest in the status quo. And though there are innovative leaders within health care, with big ideas, they often lack the support to implement them. "Patients and the public are what's going to transform and change the health care system, end of story," said Power. "You see any big social movement, you see any major transformation that has happened in this world in our history, it's because the public stood up and said: no longer."

Roger Collier, CMAJ 